\title{
Kripto Paralarda Miktar Teorisi Uygulaması: Bitcoin Örneği ve Covid-19 Salgının Etkisi
}

\section{Application of Quantity Theory of Money in Cryptocurrencies: Example of Bitcoin and the Impact of Covid-19}

\author{
Seren FIRAT ${ }^{1} \oplus$, Esat DAŞDEMIR ${ }^{2} \odot$
}

\section{öz}

Bu çalışma kripto paralar için miktar teorisinin geçerliliğini sınamaktadır. Son yıllarda para piyasalarında gündeme gelen kripto paralar, paranın yeni bir türü olarak algılanmaktadır. Paranın tarihsel gelişimi ele alındığında kripto paraların çıkışı, geleneksel paraların kullanılmasına neden olan intiyaçlar ile benzerlik göstermektedir. Dolayısıyla literatürdeki para kurallarının geleceğin parası olarak adlandırılan kripto paralar için test edilmemesi büyük bir eksikliktir. Çalışma kapsamında kripto paraların çıkışı ve kullanıma başlaması diğer para türleri ile karşılaştırmalı olarak ele alınmış ve kripto paralar için Fisher'in miktar teorisi modeli test edilmiştir. Temel kripto para birimi olan Bitcoin'in piyasa değeri ve miktarı kullanılarak Ağustos 2010 ve Nisan 2021 dönemini kapsayan aylık frekanslı veriler ile zaman serisi analizi yapılmıştır. Yapılan analiz sonucu Bitcoin miktarı ve değeri arasında doğrusal bir ilişki olduğu anlaşılmıştır. Bu durumun temel nedeni blok zincir yöntemini kullanan kripto paralardaki madencilik faaliyetleri ile açıklanmıştır. Yapılan ekonometrik analiz Covid-19 salgınının Bitcoin miktarı ve piyasa değeri arasındaki doğrusal ilişkiyi güçlendirdiğini göstermiştir. Analiz sonuçlarının anlaşılması ve literatürdeki boşluğu doldurmak amacıyla çalışma kapsamında blok zincir yöntemini kullanan kripto paralar için para arzı, emisyon ve senyoraj geliri gibi konulara değinilmiş ve bu süreçlerin işleyişi açıklanmıştır. Bu çalışma kripto paralarda Fisher Miktar Teorisinin geçerli olmadığını gösteren öncül bir kaynaktır.

Anahtar kelimeler: Kripto para, Miktar teorisi, Covid-19 JEL Sınıflandırması: E51, E41 G10

\section{ABSTRACT}

This study tests the validity of the quantity theory for cryptocurrencies. They have been on the agenda of financial markets in recent years, and they are perceived as a new type of money. Considering the historical development of money, the emergence of cryptocurrencies is similar to the evolution of traditional currency. Therefore, great deficiency exists in the in the existing literature because money rules are not tested for cryptocurrencies, which have been referred to as the money of the future. Within the scope of this study, releases and the use

${ }^{1}$ Öğretim Görevlisi, İstanbul Gelişim Üniversitesi, Meslek Yüksekokulu/Lojistik Programı, İstanbul, Türkiye

${ }^{2}$ Öğretim Görevlisi, İstanbul Gelişim Üniversitesi, Meslek Yüksekokulu/Dış Ticaret Programı, İstanbul, Türkiye

ORCID: S.F. 0000-0001-7269-2905;

E.D. 0000-0001-8950-2020

Sorumlu yazar/Corresponding author: Seren FIRAT,

İstanbul Gelişim Üniversitesi, Meslek Yüksekokulu/Lojistik Programı, İstanbul, Türkiye E-posta/E-mail: skaya@gelisim.edu.tr

Başvuru/Submitted: 12.02.2021

Revizyon Talebi/Revision Requested: 10.05.2021

Son Revizyon/Last Revision Received: 14.05.2021

Kabul/Accepted: 15.05 .2021

Atıf/Citation: Firat, S., \& Dasdemir, E. (2021). Kripto paralarda miktar teorisi uygulaması: Bitcoin örneği ve Covid-19 salgının etkisi. Istanbul Iktisat Dergisi - Istanbul Journal of Economics, 71(1), 81-102. https://doi.org/10.26650/ISTJECON2021-879423 
of cryptocurrencies were comparatively discussed with other types of money, and Fisher's quantity theory model was tested for crypto coins. Using the market value and amount of Bitcoin, the time series analysis is performed with monthly frequency data covering a period from August 2010 to April 2021. As a result of the analysis, it is understood that a linear relationship prevails between the amount and value of Bitcoin. The main reason for this situation can be explained by cryptocurrency mining activities that use the blockchain method. the econometric analysis shows that the Covid-19 outbreak has strengthened the positive relationship between
Bitcoin amount and market value. To understand the results of the analysis and fill the gap in the literature, issues such as money supply, emission and seigniorage income for cryptocurrencies are discussed and the operating processes for each are explained. This study contributes to the literature by showing that the Fisher Quantity Theory is not valid for cryptocurrencies.

Keywords: Cryptocurrency, Quantity theory, Covid-19

JEL Classification: E41, E51, G10

\section{EXTENDED ABSTRACT}

Several aspects of cryptocurrencies have been discussed such as the emergence of cryptocurrencies, the method of mining and use cases, and their role in the economy yet, uncertainty remains. Although the qualities of cryptocurrencies as a unit of currency have been discussed, numerous monetary theories have not been tested on them; the quantity theory, which reveals the relationship between the purchasing power and the amount of money, is one of these theories. Within the scope of this study, Fisher's (1911) quantity theory, has been tested on Bitcoin. Fisher's quantity theory, which highlights supply-side approach, has revealed that a difference exists between traditional moneys and cryptocurrencies. The reason behind this difference is thereby evaluated in this study.

The analysis of the quantity theory for Bitcoin has revealed that the findings are in line with this study's hypothesis. According to the results of the time series analysis covering the period from August 2010 and April 2021, a positive relationship has been determined between the amount of Bitcoin and its market value. Newey-West (1987) transform has been used in the regression model. According to the results, before the Covid-19 outbreak (August 2010 - October 2019), $1 \%$ increase in the amount of Bitcoin increases its market value by $10.36 \%$ while the figure is $27.05 \%$ after the Covid-19 outbreak (December 2019 - April 2021). Almost all cryptocurrencies use the blockchain method. Issues such as determination of money supply, the volume of emission, and ownership of 
seigniorage income are clarified in this study. It cannot be ignored that the difference between the cryptocurrency reserves, which can be mined to certain or uncertain level, may have different effects. Therefore, in terms of money supply, significant differences exist between traditional money and cryptocurrencies. Determining these differences is a crucial contribution to the extant literature.

Cryptocurrencies are very similar to other money type in terms of the reasoning behind their invention. In line with this notion, it is expected that cryptocurrencies will remain on the future agenda. Therefore, it is considered essential for countries, firms, and individuals to add cryptocurrencies in their portfolios in the long run. The methods and rules used by cryptocurrencies differ, which affects many factors such as their valuation. Additionally, different reserve amounts are determined for each cryptocurrency, and the maximum reserve amount that can be mined is predetermined. As of April 2021, no cryptocurrency has an uncertain maximum level of reserve. However, this study argues that cryptocurrencies with uncertain reserve levels can further stimulate the interest of individuals. In addition, mining activities, based on numerical rules instead of operations that require electricity consumption, will provide sustainability to reduce the production and transaction costs of cryptocurrencies. Hence, cryptocurrencies that will be launched in the future money markets must consider these factors.

Following is the outline of the paper: in Section 1 the history and emergence of cryptocurrencies are compared with other types of money; in Section 2, concepts such as the money supply, emission and seigniorage income are explained and how and by whom these terms are provided in cryptocurrencies are clarified; in Section 3, basic quantity theories are provided; in Section 4, the method and analysis results are presented; in Section 5, the results obtained from the analysis are evaluated; and in Section 6, the study concludes with estimates and suggestions, which are in line with the findings. 


\section{Giriş}

Literatür ile yakın zamanda tanışan kripto paraların ortaya çıkış biçimi, kullanım ve üretim yöntemi, ekonomideki rolleri gibi pek çok konu başlığı tartışma ve belirsizliğini korumaktadır. Kripto paraların para olma nitelikleri tartışılmakla birlikte, pek çok para teorisinin kripto paralar üzerinde test edilmediği görülmektedir. Paranın alım gücü ve miktarı arasındaki ilişkiyi ortaya koyan miktar teorisi de bunlardan biridir.

Çalışma kapsamında temel miktar teorilerinden biri olan Fisher (1911) miktar teorisi Bitcoin üzerinde sınanmıştır. Arz yönlü yaklaşımlardan biri olan Fisher'in miktar teorisi, geleneksel paralar ile kripto paralar arasında farklılık olduğunu göstermiştir. Bu farklılığın nedenleri çalışma kapsamında değerlendirilmiştir.

Bu çalışma kripto paralarda para miktarını belirleyen madencilik faaliyetinin yapısı nedeniyle Fisher miktar teorisinin kripto paralarda geçerli olmadığını ortaya koyarak literatüre katkı sağlayacaktır. Yapılan analiz sonucu kripto paraların miktarı ile değeri arasında ters yönlü ilişki olmadığı, kripto para miktarı ile değeri arasında doğrusal bir ilişki bulunduğu tespit edilmiştir. Bu bağlamda çalısma literatürde öncü olacaktır.

Çalışmanın ilk bölümünde kripto paraların tarihçeleri ve ortaya çıkış biçimleri diğer para türleri ile karşılaştırılmıştır. Íkinci bölümde para arzı, emisyon ve senyoraj geliri gibi kavramlar açıklanarak bunların kripto paralarda nasıl ve kimler tarafından sağlandığı açıklanmıştır. Üçüncü bölümde temel miktar teorilerine ve literatür özetine yer verilmiştir. Dördüncü bölümde yöntem ve analiz sonuçları ortaya konmuştur. Beşinci bölümde ise analizden elde edilen sonuçlar değerlendirilmiştir. Sonuç bölümünde ise çalışma kapsamında elde edilen çıtılar doğrultusunda tahmin ve önerilere yer verilmiştir.

\section{Kripto Paranın Tarihçesi}

Ekonominin gelişmesi, ticari işlemlerin artması, teknolojinin gelişmesi ve yaygınlaşması gibi unsurlar finans ve ödeme araçlarını önemli ölçüde geliştirmiştir. 
Geçmiş ekonomik yapılara göre daha sık gerçekleşen ticari işlemler, daha kullanışı ödeme araçları da gündeme getirmiştir. Böylece paranın kullanımını kolaylaştıracak işlevleri paraya kazandırma gerekliliği doğmuştur. Bu gereklilik sonucunda temsili, kaydi ve kripto paralar ortaya çıkmışır. Başlangıçta arzı mal paraya bağlanan temsili para, tarihsel süreç içerisinde daha bağımsız duruma gelmiştir. Temsili para türleri sırasıyla; altın ve gümüşs sertifikaları, banknotlar, kâğıt para ve bozuk para şeklinde gelişmiştir. Para, tarihsel süreç boyunca dönemin ihtiyaçlarına göre kendini sürekli olarak geliştirmiştir. Finansal piyasaların ve bankacılık sektörünün gelişmesi ve borç-alacak ilişkilerinin yaygınlaşması sonucu; "vade" unsurunu da barındırabilen daha kullanışlı ve esnek ödeme araçlarına gereksinim doğmuştur. Böylece temsili paraların yanında kaydi paralar da ortaya çıkmış ve giderek yaygınlaşmıştır.

Kaydi paraları yaratan bankalar, borç ilişkisini kayda almak amacıyla 15. yüzyılda ortaya çıkmış olup, kredi verme ve risk alma konularında önde gelen kuruluşlardır. Bireylerin mevduatlarını yatırma taleplerinde ilk tercih edilen yer olmaları nedeni ile bankalar ödeme sistemine hâkim yapıdadırlar. Ancak Neoliberal politikalar sonucu denetimsizce büyüyen bankacılık sektörü Türkiye Cumhuriyeti'nde 2001 yılında, dünyada ise 2008 yılında yıkıcı krizlerle karşılaşmıştır (Şişman, 2015, s. 346). Meydana gelen bu finansal krizler bankacılık sistemine olan güveni sarsmıştır (Özdemir \& Kayhan, 2019, s. 447). Özellikle 2008 yılında yaşanan küresel ekonomik kriz tüketicilerin bankacılık sistemine olan güvenini derinden etkilemiştir. Ayrıca küreselleşme ile birlikte temsili ve kaydi paraların özellikle ulusal ekonomik sınırlara takılması, bu tür paralarda ortaya çıkan yüksek işlem ücretleri, transfer ve saklama işlevleri daha kolay olan paraların tercih edilmek istenmesi ve elektronik ticarette kullanılmak üzere yeni para türlerine yönelik bir gereksinim kendini göstermiştir. Bu gereksinimler kripto para olarak adlandırılan para türünü gündeme getirmiştir. Kripto paralar dijital ve sanal para birimi olarak tanımlanmaktadır. Ancak her dijital ve sanal para birimi kripto para olarak tanımlanamamaktadır. Kripto para; şifrelenmiş, merkezi olmayan ve bir otorite tarafından denetlenemeyen para birimidir. 2008 yılında Satoshi Nakamoto tarafından ortaya çıkarılan ve ilk kripto para olarak nitelendirilen Bitcoinden önce pek çok başarııız kripto para denemesi gerçekleştirilmiştir. Başarııızlıkla sonuçlanan ve sürdürülemeyen bu girişimler Bitcoinin elde ettiği başarıya önemli katkılar 
sağlamıştır. Teknolojinin giderek yaygınlaşması ve tüketicilerin farklı finansal araçlara ihtiyaç duymaya başlaması sonucunda kripto para birimlerine olan ilgi gün geçtikçe artmaktadır.

Kripto para, şifreli para anlamına gelmekte olup, 'crypto' (kripto) ve 'currency' (para) kelimelerinin birleşmesi ile oluşmuştur (Turan, 2018, s. 2). Kripto para, kriptografiye dayanan bir ödeme sistemidir. Kripto para karşılıklı dijital mübadele işlemini gerçekleştirmektedir (Marian, 2016, s. 923). Kripto paralar, merkezi olmayan kripto sistemlerde, kamuya açık ve herkes tarafından bilinen yöntemlerle sistemin kuruluş aşamasında belirlenen oranlarda üretilmektedirler. Dolaşıma sunulan kripto para miktarı ve para arzının şekli ve zamanlaması, kripto sistemin kuruluş aşamasında belirlenmektedir (Çarkacıoğlu, 2016, s. 9). Kripto paralar, geleneksel ödeme şekillerine göre daha düşük maliyetli ve daha hızlı işlem yapma imkânı sunmaktadır. Ayrıca kripto para birimleri uluslararası çapta işlem yapmaya müsaade ettiğinden döviz bozdurma maliyetlerini de ortadan kaldırmaktadır. İşlemlerin her iki tarafın onayına ihtiyaç duyması ise hileli işlemlerin azaltılmasını sağlamaktadır (Tredinnick, 2019, s. 39).

1980'li yılların sonu itibariyle pek çok araştırmacı kripto para birimlerini oluşturmak amacıyla kriptografiyi kullanmaya başlamıştır. İlk kripto para denemeleri genellikle ulusal para birimi veya altın gibi değerli metallerle desteklenmiştir. Bu denemeler başarılı olmasına rağmen merkezi otoriteye bağlı çalışmaları sebebi ile hükümet müdahalelerini ve dışarıdan gelen saldırıları ortadan kaldıramamıştır (Antonopoulos, 2015, s. 3). Yine bu yıllarda kripto para projelerinde, 'Sayısal verileri kendi içerisinde nasıl değerli kılabiliriz?' sorusu ortaya çıkmıştır. Bağımsız bir kripto para yaratmak için; çoğaltma, eşgüdüm ve benimseme konularında 3 temel problem ile karşı karşıya kalınmıştır (Brunton, 2019, s. 62).

Bağımsız bir dijital para birimi arayışı ilk olarak, Timothy May, Eric Hughes ve John Gilmore tarafından 1992 yılında başlamışırı. Grup kendine 'Cypherpunks' adını vermiş ve kriptolojik yöntemlerin işletmelerin doğasını ve ekonomik işlemlere hükümetin müdahalesini temelden değiştireceğine inanmıştır. Aynı yıl kurucu 
ortaklardan Eric Hughes, bir hafta içerisinde, şifrelenmiş e-postalar alabilen, tüm tanımlayıcı işaretleri silen ve bunları bir abone listesine geri gönderen bir program yazmıştır. Cypherpunklar nakit işlem ve takas haricinde işleyen finansal sistemde işletmeler ve hükümetler ile gerçekleştirilen faaliyetlerin mahremiyet içinde olmadığını bu sebeple yeni bir sistem kurulması gerektiğini savunmuşlardır. Cypherpunklar kripto para birimleri için potansiyel kullanımları gerçekleştirmek isterken, bu alanda araştırma yapan diğer araştırmacılar sistemdeki teknik sorunları çözmek için çaba göstermiştir. Wei Dai, B-Money'i, Nick Szabo Bit Gold'u ve David Chaum DigiCashi yaratmıştır. Bitcoin, şifrelenme ve madencilik süreçlerinde kendinden önce ortaya çıkmış olan Bit Gold ve B-Money'den esinlenmiştir. Ancak bu dijital para birimleri yaygın bir destek elde edememiştir (Peck, 2012, s. 52). 2008 yılına kadar kripto para ile ilgili yapılan çalışmalar başarısızıkla sonuçlanmış olsa da hem Bitcoini başarıya ulaştıracak kritik noktaların daha kolay tespit edilmesini hem de insanların dikkatini çekmeyi sağlamıştır.

Ilk kripto para 2008 yılında Mortgage krizinin hemen sonrasında Satoshi Nakamoto takma ismini kullanan kişi veya kişiler tarafından 'Bitcoin: Eşten Eşe Elektronik Nakit Ödeme Sistemi' başlıklı bir teknik çalışma ile açıklanmıştır. Bitcoin ile ilk işlem 2009 yılında yapılmış olup, kripto para kullanımı bu tarih itibari ile hayatımıza girmiş bulunmaktadır (Nakamoto, 2008, s. 1-3). Nakamoto'nun yarattığı sistem kriptoloji ile ilgilenen pek çok kişinin ilgisini çekmiş ve gördüğü destekler sonucunda ilk kaynak kodunu 3 Ocak 2009'da 30,000 satırlık kod ile Bitcoin'in başlangıcını ilan etmiştir. Hal Finney, Nakamoto'ya kod konusunda yardım eden ilk destekçisi olmuştur. Finney ve diğer geliştiricilerin destekleri ile sisteme dahil olanların sayısı her geçen gün artmıs olup, 2010 yılına gelindiğinde küçük kesim de olsa bazı tüccarlar Bitcoin'i bir ödeme aracı olarak kabul etmeye başlamıştır (Aksoy, 2018, s. 10-12).

Kripto para birimleri piyasaya sürülmeden önce de dijital ve sanal para birimleri bulunmaktaydı ancak bu paraların özellikleri farklıdır. Bitcoin ve türevleri gibi kripto paralar dışındaki dijital ve sanal paralar, kendi başlarına para birimi değillerdir, temsil ettikleri ülkenin ulusal para birimine dayanmaktadır (Rotman, 2014, s. 1). 2008 yılına gelene kadar bütün para ve benzeri varlıklar merkez 
bankaları ve bir otorite tarafından piyasaya çıkarılmakta ve yönetilmekteydi. Ancak kripto paranın piyasaya sunulmasında herhangi bir otoriteye ihtiyaç duyulmaması ve Bitcoinin elde ettiği başarı beraberinde pek çok farklı özelliklere sahip benzer kripto para birimlerini ortaya çıkarmıştır. Kripto paraları; Bitcoin, alternatif ve coin kelimelerinin birleşiminden oluşan altcoin ve token şeklinde sınıflandırmak mümkündür. Altcoinlerin değerleri Bitcoin ya da bazı değerli kripto paralarla ölçülürken, Bitcoinin değeri ABD doları ile ölçülmektedir. Günümüzde piyasada 5000'den fazla kripto para birimi mevcuttur. Coin Market Cap web sitesi verilerine göre 14 Mayıs 2021 tarihinde piyasa değeri en yüksek üç kripto para sırasıyla Bitcoin (950 Milyar ABD Doları), Ethereum (464 Milyar dolar) ve Binance Coin (606 Milyar dolar) şeklindedir. Volatilitesi oldukça yüksek olan kripto paralarda bu sıralama saatler içerisinde değişebilmektedir. Bu nedenle teknolojisi ve niteliği en çok tartışılan kripto paraları özetlemek daha doğru olacaktır.

a. Bitcoin: Blok zincir adı verilen dağıtılmış bir defter teknolojisindeki işlemleri kaydeden merkezi olmayan bir sistem olan ilk dijital kripto para birimi olmaktadır. 2008 yılında Satoshi Nakamoto tarafından ortaya çıkarılmıştır. Kullanıcıların veya dış bağlantıların manipülasyonuna yönelik müdahalelerine karşı gerekli tedbirlerin alındığı ve merkezi bir sisteme bağlı olmaksızın çalışabilen bir sanal para birimi olarak ortaya çıkmıştır. Bitcoin para birimi sanal olmasının yanı sıra arkasında bulunan Blok zincir adı verilen kayıt sisteminin güçlü kriptografi teknikleri ve tek bir merkez yerine bütün kullanıcılara dağıtılmış veri yapısı ile de dikkat çekmeyi başarmıştır (Usta \& Doğantekin, 2017, s. 17-18).

b. Ethereum: Ethereum, Bitcoin'den sona ikinci büyük piyasa değerine sahip kripto paradır. Bitcoin gibi blok zincir yönteminden faydalanan ve merkezi otoriteye bağlı olmayan Ethereum, blok oluşturma süresinde farklılık göstermektedir. Ethereum'da blok oluşturma 2-8 saniye gibi bir süreyken, Bitcoinde bu süre 10 dakikayı bulmaktadır. Blok oluşturmada ortaya çıkan bu süre farkı Ethereum'un ortaya çıkma sebeplerindendir. Bu kripto paranın özelliklerinden biri de akıllı sözleşmelerdir. Akıllı sözleşmeler, taraflar arasındaki sözleşmenin doğrudan kod satırlarına yazıldığı sözleşmelerdir. Bu sözleşmeler merkezi olmayan blok zincir yöntemi üzerinde çalıştırılmaktadır. 
Gerçekleştirilen işlemler izlenebilir ancak geri döndürülemezdir (Sontakke \& Ghaisas, 2017, s. 15).

c. Binance Coin: Bu kripto para Binance Exchange tarafından verilen bir platform belirteci olup, ERC20 standardı ile Ethereum blok zinciri üzerinde 2017 yılında ortaya çıkmıştır. Binance Coin, üç milyonu geçen kayıtlı kullanıcısı ile dünyanın en büyük kripto para borsasında yer almaktadır. Binance Coin akıllı sözleşmesi, Ethereum platformunda en çok kullanılan ERC20 sözleşmelerinden birisi olmuştur (Sun \& Yu, 2020, s. 12). Ancak daha sonra Binance kendi zincirini kurarak BEP2 tabanlı bir alt yapıya geçmiştir. Mevcut ERC20 tokenlar yakılarak BEP2 tokenlara dönüştürülmüştür. Binance Coin, madenciliği yapılmayan bir kripto para türüdür. Tüm Binance Coin miktarı Binance borsası tarafından ilk gün üretilmiş ve \%50'si halka satılmıştır.

d. Ripple: 2017 yılı itibari ile yükselişe geçen Ripple günümüzde en büyük üçüncü kripto paradır. Nakit paranın bankalar tarafından özellikle uluslararası olarak daha düşük maliyete ve daha hızlı aktarmalarını sağlamak amacı ile 2012 yılında piyasaya çıkmışıı. Uluslararası ödeme yöntemlerinin geleneksel anlamda yavaş ve yüksek işlem maliyetleri ile gerçekleştirilmesi Ripple'ın önemini artırmıştır (İnci \& Lagasse, 2019, s. 102). Kripto paranın işlem maliyeti 0.0011 dolar ile Bitcoin işlem maliyetinden daha düşüktür. Bu kripto para ile düşük işlem maliyeti ile kısa sürede işlem yapma ve ödemeleri yüksek hızda gerçekleştirmek mümkündür. Bu avantajlar sayesinde büyük bankalar ile finans hizmeti sunan firmalar tarafından tercih edilmektedir. Ripple'ı Bitcoinden ayıran diğer bir özelliği ise blok zincir yöntemini kullanmıyor olmasıdır. Ripple dağıtımı Ripple laboratuvarları tarafından gerçekleştirilmektedir (Armknecht, Karame, Mandal, Youssef \& Zenner, 2015, s. 166).

İ̧lem hacmi en yüksek üç kripto paranın 1.6 trilyon doları aşan piyasa değerinin yanı sıra 2013 yılında tanıtılan Dogecoin kripto para birimi de günümüzde dikkat çekmeye başlamıştır. Litecoin tabanlı kripto paranın kurucusu Billy Markustur. Maskotu Shiba Inu cinsi bir köpek resmi olan Dogecoin bir şaka para birimi olarak ortaya çıkmıştır. Dogecoin'in resmi tanıımı 6 Aralık 2013 tarihinde yapılmış ve orijinal toplam arzın 100 milyar Dogecoin olması amaçlanmıştır. Ancak sonrasında 
Dogecoin ağının sonsuz Dogecoin üreteceği ve bu şekilde doğal bir enflasyon ivmesi oluşturacağı açıklanmıştır (Chohan, 2021, s. 2). Dogecoin, çevrimiçi olarak hızlı şekilde para göndermeyi amaçlayan, merkezi olmayan ve eşler arası dijital bir para biridir. Litecoin'in Scrypt protokolüne dayanmakta olan Dogecoin, blok oluşturma süresi ile Litecoinden ayrılmaktadır. Litecoin'de blok oluşturma süresi 2.5 dakikayı bulurken bu süre Dogecoin'de 1 dakikadır. Litecoinden daha hızı olan Dogecoin düşük işlem maliyeti ve hızlı işlem süresi avantajı yaratmaktadır. Kullanımını yaygınlaştırmak amacıyla Dogecoin ile ilgili ipuçları paylaşan kullanıııları teşvik etmek için ödüller verilmektedir (Young, 2018, s. 2-4). Piyasaya sürüldüğü ilk yıl 0.00056 dolardan temin edilebilen Dogecoin'in 2018 yllı itibariyle birim değeri 0.015 dolara kadar yükseltmiştir. Şubat 2021 itibari ile 0.08 dolar seviyesinde işlem görmektedir. Coin Market Cap web sitesi verilerine göre Mayıs 2021 tarihi itibari ile toplam kripto para borsasının hacmi 2.3 trilyon ABD Dolarını aşmaktadır.

Piyasa değeri hızla artan kripto paraların önünde duran bir diğer engel ise enerji tüketimleri konusudur. Çevre kirliliği ve ekonomik büyüme arasındaki ters yönlü ilişki (Ay, 2021, s. 276) göz önüne alındığında madencilik faaliyetlerinin önemli düzeyde enerji tüketmesi ve çevre kirliliğine neden olması durumu; kripto paraların makro ekonomik anlamda sürdürülebilir büyümeye olumsuz etki edeceği öngörülebilmektedir. Bu nedenle yasal kısıtlamalardan ziyade kripto paraların önündeki en büyük engellerden biri enerji tüketimi konusudur.

\section{Kripto Paralarda Emisyon ve Senyoraj Geliri}

Oldukça güncel bir konu olan kripto paralarda bazı parasal kavramların nasıl bir biçim aldığını belirtmek gerekmektedir. Kripto paraların talep edilme nedenleri geleneksel paralar ile benzerlik gösteriyor olsa da üretim ve kullanma yöntemleri açısından keskin farklılıklar göstermektedir. Bu başlık altında kripto paralarda senyoraj gelirinin sahibi, para arzı ve emisyon hacminin nasıl belirlendiği gibi konulara değinilmiştir.

Senyoraj, paranın üretim maliyeti ile nominal değeri arasındaki farktır. Anlaşılacağı üzere senyoraj, para ihraççısının kârını ifade etmektedir. Para 
ihraççısının elde ettiği bu kâr senyoraj geliri olarak adlandırılmaktadır. Temsili paralarda senyoraj gelirinin sahibi çoğunlukla, hükümet tarafından yetkilendirilen para otoritesi konumundaki merkez bankalarıdır. Para otoritesi, piyasaya çıkarılacak parayı diğer bir deyişle emisyon hacminin belirleyicisidir ve teorik olarak bunu istediği biçimde kontrol edebilir.

Blok zincir teknolojisini kullanan kripto paralarda ise emisyon hacminin oluşumu ve senyoraj gelirinin elde ediliş biçimi mal paralar ile oldukça benzerlik göstermektedir. Altın ve gümüş gibi mal paralarda senyoraj geliri madencilik faaliyetleri ile ortaya çıkmaktadır. Benzer şekilde, blok zincir teknolojisini kullanan kripto paralarda madencilik olarak adlandırılan faaliyet sonucu emisyon hacmi belirlenmektedir. Para transferlerinin kaydı tutulan bloklarda transferler şifreli, diğer bir deyişle kriptolu kodlar aracılığı ile kaydedilir. Bu kayıtlar belli koşulları sağlıyorsa, kaydı ilk gerçekleştiren madenci belirli bir miktar kripto para ile ödüllendirilir. Böylece madencilik faaliyetlerini gerçekleştirmek maksadıyla harcanan enerji ve kullanılan teknik ve teknolojik araçların yıpranma payları düşüldükten sonra senyoraj geliri ortaya çıkar. Madencinin tek kazancı senyoraj geliri değildir. Kaydedilen para transferleri için de madenci belirli bir gelir elde edebilir. Madencinin geliri, kripto para teknolojisinin biçimine bağlıdır. Söz gelimi Bitcoinde para arzı 21 milyon Bitcoin ile sınırlandırılmış ve bu sınıra 2140 yılında ulaşılacağı tahmin edilmektedir (Hurlburt \& Bojanova, 2014, s. 12). Bu sınıra ulaşıldığında madencilerin tek geliri işlem transferlerinden aldıkları ödemeler olacaktır. Teorik olarak internet ağı erişimine ve temel donanımlara sahip olmak madencilik faaliyetlerini gerçekleştirmek için geçerli bir koşuldur. Ancak kripto paralarda madencilik faaliyetleri yasalarla sınırlandırılabilmekte, hatta kripto paranın alım satımı ile birlikte yasaklanabilmektedir (Stolbov \& Shchepeleva, 2020, s. 273).

\section{Miktar Teorisi ve Kripto Paralarda Para Arzı}

Paranın miktarı ve değeri arasında ilişki kuran miktar teorisinin ortaya çıkışı tam olarak bilinmese de literatüre 16. yüzyılda Jean Bodin'in çalışmalarıyla girmiştir. Ardından 18. yüzyıla kadar John Locke, Richard Cantillon ve David Hume teoriye 
katkı yapmıştır (Humphrey, 1974, s. 2). Günümüze doğru yaklaştığımızda Irving Fisher (1911), Arthur Pigou (1917), Alfred Marshall (1923), John Maynard Keynes (1937) ve Milton Friedman (1969) gibi bilim insanları miktar teorisine önemli katkılar sunmuştur.

Diğer konularda olduğu gibi miktar teorisinde de arz ve talep yönlü bakış açısı bulunmaktadır. Başlarda arz ağılıklı olan para teorileri, Keynes ve Cambridge yaklaşımlarıyla talep yönlü bir bakış açısı kazanmıştır. Klasik yaklaşımın parayı yalnızca işlem amaçlı talep edilen bir araç olarak görmesi nedeniyle para talebine yönelik yapılan yorumlar uzunca bir süre yetersiz kalmıştır. Diğer bir deyişle para talebinin, paranın değerini belirleyebileceği senaryosu görmezden gelinmiştir.

Para teorilerinde arz yönlü yaklaşım tek paranın söz konusu olduğu sistemlerde geçerli sayılabilir. Ancak para ve para ikamelerinin çeşitliliğinin artması sonucu para talebinin paranın değerini belirlemekteki açıklayıcı gücü daha da artırmaktadır. Dolayısıyla günümüzde paranın alım gücünü açıklamakta talep yönlü yaklaşımlar daha kullanışlıdır. Ancak kripto paraların arzı konusunda geleneksel paralardan farklılaşması nedeniyle, bu tür paraların değerini açıklarken arzlarının incelenmesini de gerekli kılmaktadır.

Literatürde yer alan temel miktar teorilerinin kullandığı denklemler incelendiğinde yapılan modellemelerin birbirine oldukça yakın olduğu anlaşılmaktadır. Fisher (1911) miktar teorisinde paranın değeri, para arzı ile ilişkilidir. Para arzındaki ya da para miktarındaki artışlar doğrudan doğruya fiyatları artırmaktadır. Fisher miktar teorisi denklemi aşağıdaki gibidir.

$$
\mathrm{M} \times \overline{\mathrm{V}}=\mathrm{P} \times \overline{\mathrm{T}}
$$

Fisher denkleminde " $M$ " ya da "money supply" para arzı ya da miktarı, "V" ya da "velocity of circulation" paranın dolanım hızını, "P" ya da "price level" fiyatlar genel düzeyini, " $T$ " ya da "Transactions" parasal ödemenin söz konusu olduğu işlemleri belirtmektedir. Fisher, klasik yaklaşımın varsayımlarını benimsemesinden ötürü $V$ ve $T^{\prime}$ yi sabit kabul etmiştir. Bundan dolayı, para arzındaki her değişim, aynı oranda fiyatlar genel düzeyini etkilemektedir. 
Alfred Marshall ve Arthur Pigou gibi Cambridge Üniversitesi akademisyenlerinin geliştirdiği ve benimsediği miktar teorisinde ise paranın değerini açılamakta talep yönlü bir yaklaşım benimsenmiştir (Shimazu, 1969, s. 53-54). Para talebini öne çıkarması nedeniyle para tutumu yaklaşımı olarak da anılmaktadır. Marshall'ın yaklaşımına istinaden geliştirilen denklem aşağıdaki gibidir.

$$
\mathrm{M}=\overline{\mathrm{k}} \times \mathrm{Y}+\overline{\mathrm{k}}^{\prime} \times \mathrm{A}
$$

Bu denklemde Fisher denkleminden farklı olarak kullanılan " $k$ " bireylerin gelecek harcamalarında kullanmak amacıyla ellerinde tuttukları para miktarını, " $k$ '" servetin para olarak tutulan kısmı, " $A$ " toplam servet değerini göstermektedir. Marshall'ın bu denkleminin daha bilinen ve daha basitleştirilmiş formu ise aşağıdaki gibidir.

$$
\mathrm{M}=\overline{\mathrm{k}} \times \mathrm{P} \times \overline{\mathrm{Y}}
$$

Marshall'ın bu denklemi Cambridge yaklaşımı olarak da kabul görmektedir. Denklemde kullanılan " $Y$ " tam istihdam gelir düzeyini göstermektedir ve sabittir, " $k$ " ise nakit olarak tutulmak istenen para miktarını göstermektedir. Diğer bir deyişle $k$, dolaşımda olmayan paradır. Bu bağlamda $k$, “1/V” olarak da gösterilebilir. Yine Cambridge akademisyenlerinden Arthur Pigou'nun yaklaşımına göre miktar teorisi denklemi aşağıdaki gibidir.

$$
\mathrm{P}=\frac{\mathrm{k} \times \mathrm{R}}{\mathrm{M}}
$$

Bu denklemde farklı olarak kullanılan " $R$ " toplam reel geliri, diğer bir deyişle tam istihdam gelir düzeyini göstermektedir ve önceki denklemlerde yer alan "T" ve "Y" değişkenleri yerine ikame edilmiştir.

Görüleceği gibi Fisher'in arz yönlü modellemesini ve Cambridge akademisyenlerinin talep yönlü modellemesi kullandıkları değişkenleri itibariyle benzerlik gösterse de modellerin açıklayıcı ve açılanan değişkenleri farklılık göstermektedir. Kripto paralarda arz yönlü ya da talep yönlü yaklaşımlardan hangisinin etkin bir açıklama gücünün olduğu tartışılabilir. Bu çalışmada kripto para arzının, kripto para değeri arasındaki ilişki incelenmiştir. Bunun nedeni kripto para paraların üretilme sürecidir. Önceki bölümde açıklandığı üzere, kripto 
paraların değerlenmesi madencilik faaliyetlerine bağlıdır. Madencilik faaliyetleri ise kripto paraları cazip kılmaktadır. Dolayısıyla madencilik faaliyetlerinin arttığı dönemlerde kripto paraların değeri de artacaktır.

\section{Model ve Yöntem}

Çalışmanın hipotezi Ağustos 2010 - Nisan 2021 dönemi kapsamında aylık frekanslı veriler ile zaman serileri analizi yöntemleri kullanılarak test edilmiştir. Covid-19'un kripto paralara önemli bir etkisi olduğu düşünüldüğünden dolayı öne sürülen hipotez için Covid-19 salgınının etkisi ölçülmek istenmektedir. Bu amaçla çalışmaya Kasım 2019 ve sonrası dönem için kukla değişkenler eklenmiştir. Ayrıca kripto paralara olan talebin her yıl için spesifik etkileri olabilmektedir. Bu etkilerin tespiti adına bazı yıllar için oluşturulan kukla değişkenler modele eklenmiştir. Bu yıllar, anlamsız çıkan kukla değişkenlerin modelden dışlanması ile tespit edilmiştir. Yapılan analiz ile çalışma hipotezini destekler sonuçlar elde edilmiştir. Tablo 1, analizde kullanılan değişkenlerle ilgili bilgileri içermektedir. Seriler mevsimsel etkilerden arındırılmıştır.

Tablo 1: Değişken Bilgileri

\begin{tabular}{|l|l|}
\hline Değişken & Tanım \\
\hline PBtc & Bitcoin Piyasa Değeri \\
\hline OBtc & Dolaşımdaki Bitcoin Miktarı \\
\hline LPBtc & Bitcoin Piyasa Değeri (Logaritmik, Ln tabanında) \\
\hline LQBtc & Dolaşımdaki Bitcoin Miktarı (Logaritmik, Ln tabanında) \\
\hline$\Delta L P B t c$ & LPBtc değişkeninin birinci türevi \\
\hline$\Delta L Q B t c$ & LQBtc değişkeninin birinci türevi \\
\hline$K p a n$ & Covid-19 pandemi dönemi için kukla değişken (Kasım 2019 ve sonrası) \\
\hline$K p \Delta l q b$ & Kpan değişkeni ile $\Delta$ LQBtc değişkeninin çarpımı \\
\hline$K 2013$ & 2013 yılı için kukla değişken \\
\hline$K 2016$ & 2016 yılı için kukla değişken \\
\hline$K 2017$ & 2017 yılı için kukla değişken \\
\hline$K 2019$ & 2019 yılı için kukla değişken \\
\hline
\end{tabular}

Tüm test ve tahminler EViews 8 ve STATA 16 Paket Programları ile yapılmışır. Değişkenlerin durağanlığını sınayan test ve bu testlere ilişkin sonuçlar Tablo 2'de verilmiştir. 
Tablo 2: Birim Kök Testleri

\begin{tabular}{|l|l|c|c|c|c|}
\hline \multirow{2}{*}{ Birim Kök Testi Adı } & Model & $\begin{array}{c}\text { Test } \\
\text { İstatistiği }\end{array}$ & $\begin{array}{c}\text { Kritik } \\
\text { Değer (\%5) }\end{array}$ & $\begin{array}{c}\text { Test } \\
\text { İstatistiği }\end{array}$ & $\begin{array}{c}\text { Kritik } \\
\text { Değer (\%5) }\end{array}$ \\
\hline \multirow{2}{*}{$\begin{array}{l}\text { Augmented } \\
\text { Dickey-Fuller } \\
(1979)\end{array}$} & Sabitli & -2.04 & -2.88 & -3.31 & -2.88 \\
\cline { 2 - 6 } & Sabitli ve Trendli & -3.47 & -3.44 & -4.16 & -3.45 \\
\cline { 2 - 6 } & Sabitsiz ve Trendsiz & 1.22 & -1.94 & 2.08 & -1.94 \\
\hline \multirow{3}{*}{$\begin{array}{l}\text { Phillips-Perron } \\
(1988)\end{array}$} & Sabitli & -2.63 & -3.48 & -17.71 & -3.48 \\
\cline { 2 - 6 } & Sabitli ve Trendli & -3.67 & -3.45 & -21.01 & -3.45 \\
\cline { 2 - 6 } & Sabitsiz ve Trendsiz & 1.29 & -1.94 & 3.15 & -1.94 \\
\hline & & $\begin{array}{c}\text { Test } \\
\text { Augmented } \\
\text { Dickey-Fuller } \\
\text { (ADF, 1979) }\end{array}$ & $\begin{array}{c}\text { Kritik } \\
\text { Değer (\%5) }\end{array}$ & $\begin{array}{c}\text { Test } \\
\text { İstatistiği }\end{array}$ & $\begin{array}{c}\text { Kritik } \\
\text { Değer (\%5) }\end{array}$ \\
\hline \multirow{2}{*}{$\begin{array}{l}\text { Phillips-Perron } \\
(1988)\end{array}$} & Sabitli & -7.40 & -2.88 & -5.55 & -2.88 \\
\cline { 2 - 6 } & Sabitli ve Trendli & -7.44 & -3.45 & -4.74 & -3.45 \\
\cline { 2 - 6 } & Sabitsiz ve Trendsiz & -6.86 & -1.94 & -5.97 & -1.94 \\
\cline { 2 - 6 } & Sabitli & -7.32 & -2.88 & -5.55 & -2.88 \\
\cline { 2 - 6 } & Sabitli ve Trendli & -7.40 & -3.45 & -4.74 & -3.45 \\
\cline { 2 - 6 } & Sabitsiz ve Trendsiz & -6.83 & -1.94 & -5.97 & -1.94 \\
\hline
\end{tabular}

Tablo 2'den anlaşıldığı üzere ADF ve Phillips-Perron test sonuçları göstermektedir ki \%5 anlamllık düzeyinde seriler durağan değildir. Ancak birinci dereceden türevleri alındıklarında seriler durağanlaşmaktadır.

Önceki bölümde verilen Fisher miktar teorisinde yer alan varsayımlar kabul edildiğinde paranın dolanım hızı ve işlemdeki mal miktarının sabit olduğu durumda model iki değişkenli bir hal almaktadır. Dolayısıyla türevi alınan değişkenler ile tahmin edilecek model aşağıdaki gibidir.

$\Delta L P B t c_{t}=\beta_{0}+\beta_{1} \Delta L Q B t c_{t}+\beta_{2} K p \Delta l q b+K p a n+K 2013+K 2016+K 2017+K 2019+\mu_{t}$

Modeldeki " $\beta_{0}$ " sabit katsayıyı, diğer " $\beta$ " değerleri önlerinde bulundukları değişkenlerin katsayılarını, değişken adları öncesinde kullanılan " $L$ " değeri değişkenlerin logaritmalarının alındığını ve " $\mu_{t}$ " ise hata terimlerini belirtmektedir. Bu bağlamda aşağıda verilen Model 2 Covid-19 salgınının ve bazı yıllara ait özel durumların etkilerini dışlarken Model 3 Covid-19 dönemini ifade etmektedir. Yıllara ilişkin modeller ayrıca yazılmamış, çıktılar üzerinden yorumlanmışıır. 


$$
\begin{gathered}
\Delta L P B t c_{t}=\beta_{0}+\beta_{1} \Delta L Q B t c_{t}+\mu_{t} \\
\Delta L P B t c_{t}=\left(\beta_{0} \pm \text { Kpan }\right)+\left(\beta_{1} \pm \beta_{2}\right) \Delta L Q B t c_{t}+\mu_{t}
\end{gathered}
$$

Tahmin edilen modelde varsayımdan sapmalara ilişkin yapılan testlerin sonuçları Tablo 3, Tablo 4 ve Tablo 5 'te verilmiştir.

\begin{tabular}{|c|c|c|c|c|}
\hline Test Adı & Boş Hipotez & $\begin{array}{c}\text { Test } \\
\text { İstatistiği }\end{array}$ & $\begin{array}{c}\text { Olasılık } \\
\text { Değeri (p) }\end{array}$ & Karar \\
\hline $\begin{array}{l}\text { Breusch- } \\
\text { Pagan (1979) } \\
\end{array}$ & $\begin{array}{c}\text { Değişen varyans } \\
\text { sorunu yoktur }\end{array}$ & 5.01 & 0.00 & \multirow{2}{*}{$\begin{array}{c}\text { Boş hipotez reddedilmiştir } \\
\% 5 \text { anlamllık düzeyinde } \\
\text { değişen varyans sorunu } \\
\text { vardır. }\end{array}$} \\
\hline $\begin{array}{l}\text { White's test } \\
(1980)\end{array}$ & $\begin{array}{l}\text { Değişen varyans } \\
\text { sorunu yoktur }\end{array}$ & 2.85 & 0.00 & \\
\hline
\end{tabular}

Tablo 3: Değişen Varyans Varsayımına İlişskin Test Sonuçları

\begin{tabular}{|c|c|c|c|}
\hline Test İstatistiği (d) & 1.66 & Tablo Değer Aralığı, $d_{A}-d_{u ̈}(\% 5)$ & $1.378-1.717$ \\
\hline \multicolumn{2}{|l|}{ Boş Hipotez } & Kriter & Karar \\
\hline \multicolumn{2}{|c|}{ Aynı yönlü ardışık ilişki yoktur } & $0<d<d_{A}$ ise reddedilir & Reddedilemedi \\
\hline \multicolumn{2}{|c|}{ Aynı yönlü ardışı ilişki yoktur } & $d_{A} \leq d \leq d_{U}$ ise karar yoktur & Karar verilemed \\
\hline \multicolumn{2}{|c|}{ Ters yönlü ardışık ilişki yoktur } & $4-d_{A}<d<4$ ise reddedilir & Reddedilemedi \\
\hline \multicolumn{2}{|c|}{ Ters yönlü ardışık ilişki yoktur } & $4-d_{U} \leq d \leq 4-d_{A}$ ise karar yoktur & Karar verilemedi \\
\hline \multicolumn{2}{|l|}{ Ardışık ilişki yoktur } & $d_{u}<d<4-d_{u}$ ise reddedilemez & Reddedildi \\
\hline
\end{tabular}

Tablo 4: Durbin-Watson $(1950,1971)$ Test Sonucu

\begin{tabular}{|c|c|c|c|}
\hline Gecikme & Test İstatistiği & Olasılık Değeri (p) & Karar \\
\hline 1 & 3.64 & 0.06 & \multirow{4}{*}{$\begin{array}{c}\text { Boş hipotez reddedilememiştir. \%5 } \\
\text { anlamlılık düzeyinde otokorelasyon } \\
\text { sorunu yoktur. }\end{array}$} \\
\hline 2 & 2.48 & 0.09 & \\
\hline 3 & 1.95 & 0.12 & \\
\hline 4 & 1.66 & 0.16 & \\
\hline
\end{tabular}

Tablo 5: LM Otokorelasyon Test Sonuçları

Çeşitli gecikme düzeylerinde yapılan LM testlerine göre modelde \%5 anlamlılık düzeyinde otokorelasyon sorunu yoktur, ancak Durbin-Watson testi sonuçları istenilen değerleri verememiştir. White ve Breusch-Pagan testi sonuçları değişen varyans sorununu işaret etmektedir. Bu nedenle heterokedasite ve otokorelasyon varsayımlarına karşı geliştirilen dirençli tahmin yöntemleri de modelin tahmininde kullanılmıştır. 
Tablo 6: Tahmin Çıktıları

\begin{tabular}{|c|c|c|c|c|c|c|}
\hline & & 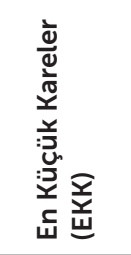 & 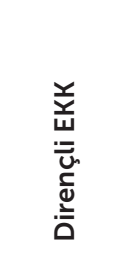 & 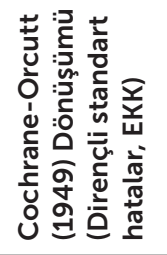 & 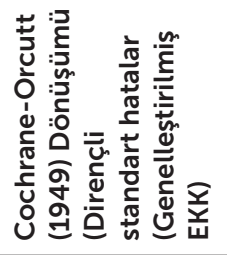 & 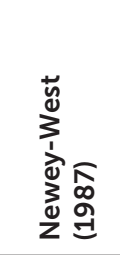 \\
\hline \multirow{2}{*}{ Sabit } & Katsayı & $0.86^{*}$ & $0.87 *$ & $0.87 *$ & $0.87 *$ & $0.87^{\star}$ \\
\hline & t Değeri & -3.12 & -3.82 & -2.83 & -2.83 & -3.82 \\
\hline \multirow{2}{*}{$\triangle L Q B t c$} & Katsayı & $10.36^{*}$ & $10.36^{*}$ & $10.27^{*}$ & $10.272^{*}$ & $10.36^{*}$ \\
\hline & t Değeri & 5.95 & 3.95 & 2.69 & 2.69 & 3.95 \\
\hline \multirow{2}{*}{ Kpan } & Katsayı & $-278.94^{*}$ & $-278.94^{*}$ & $-268.95^{\star}$ & $-268.95^{*}$ & $-278.94^{\star}$ \\
\hline & t Değeri & -2.62 & -5.30 & -4.75 & -4.75 & -5.30 \\
\hline \multirow{2}{*}{$K p \Delta l q b$} & Katsayı & 16.69* & $16.69^{*}$ & $16.09^{*}$ & $16.089^{*}$ & 16.69* \\
\hline & t Değeri & 2.62 & 5.30 & 4.75 & 4.75 & 5.30 \\
\hline \multirow{2}{*}{ K2013 } & \begin{tabular}{|l|} 
Katsayı \\
\end{tabular} & $0.36^{*}$ & $0.36^{*}$ & $0.35^{\star}$ & $.352^{\star}$ & $0.36^{\star}$ \\
\hline & t Değeri & 4.47 & 3.32 & 2.90 & 2.90 & 3.32 \\
\hline \multirow{2}{*}{ K2016 } & Katsayı & $0.14^{\star \star \star}$ & $0.14^{*}$ & $0.14^{*}$ & $0.14^{*}$ & $0.14^{*}$ \\
\hline & t Değeri & 1.71 & 4.25 & 3.46 & 3.46 & 4.25 \\
\hline \multirow{2}{*}{ K2017 } & Katsayı & $0.34^{*}$ & $0.34^{*}$ & $0.33^{*}$ & $0.34^{*}$ & $0.34^{*}$ \\
\hline & t Değeri & 3.99 & 6.57 & 5.16 & 5.16 & 6.57 \\
\hline \multirow{2}{*}{ K2019 } & Katsayı & $0.18 * \star$ & $0.18^{*}$ & $0.17 *$ & $0.17 *$ & $0.18^{*}$ \\
\hline & t Değeri & 2.06 & 3.51 & 3.00 & 3.00 & 3.51 \\
\hline \multirow{2}{*}{$R$ Kare } & Değer & $0.31^{*}$ & $0.31^{*}$ & $0.23^{*}$ & $0.23^{*}$ & - \\
\hline & F Olabilirlik & 0.00 & 0.00 & 0.00 & 0.00 & 0.00 \\
\hline
\end{tabular}

Not: * \%1 anlamlıık düzeyini, ** \%5 anlamlıık düzeyini, *** \%10 anlamlıık düzeyini göstermektedir. Sabit katsayının e tabanında ters logaritması alınmıştır. Kukla değişkenlerde etkinin yönünü tespit etmek maksadıyla bu dönüşüm yapılmadan verilmiştir.

Covid-19 salgını döneminde Bitcoin miktarının, piyasa değeri üzerindeki etkisinin negatif yönlü seyrettiği görülmektedir. Ki bu durum fazlasıyla anlamlıdır. Bunun nedeni, Covid-19 salgını döneminde bireyler kripto paraları arzı ile ilişkisiz olarak talep ederek fiyatlarını artırmışlardır. Dolayısıyla kripto para ve miktarı arasındaki etkileşimin düşmesi beklenilir bir durumdur. Diğer bir değişle, Covid-19 salgını Bitcoinin Fisher miktar teorisine göre hareket etmesine önayak olmuştur. Test ve tahminler bulgular başlığında ayrıntılı olarak incelenmiştir. 


\section{Bulgular}

Varsayımdan sapmaların tespiti amacıyla yapılan sınamalar değişen varyans ve otokorelasyon sorunu olduğunu göstermektedir. Bu nedenle yorumu yapılan tahmin çıktısı varsayımdan sapmalara izin verecek dirençli tahmincilerden biri olmalıdır. Dirençli EKK, Cochrane-Orcutt Dirençli Standart Hatalar ve Newey-West yöntemleri ile yapılan tahminlerin birbiri ile benzer sonuçlar verdiği görülmektedir. Bu bağlam da yorumlanan model Newey-West yöntemi ile tahmin edilen modeldir. Tahminden elde edilen tüm parametreler \%5 anlamlılık düzeyinde anlamlıdır. R kare değeri Cochrane-Orcutt Dirençli Standart Hatalar yönteminde \%23 olarak elde edilmiş ve $\% 5$ anlamlılık düzeyinde anlamlı bulunmuştur. Aşağıda verilen Model 4 Covid-19 salgını ve yıllara ait özel etkilerin dışlanması sonucu Bitcoin miktarı ve değeri arasındaki ilişkiyi ortaya koyarken, Model 5 Covid-19 salgını dönemi için geçerli olan tahmin sonucudur.

$$
\begin{aligned}
& \triangle L P B t c_{t}=0.87+10.36 \times \triangle L Q B t c_{t} \\
& \triangle L P B t c_{t}=0.88+27.05 \times \triangle L Q B t c_{t}
\end{aligned}
$$

Model 4'e göre Bitcoin miktarı \%1 arttığında, Bitcoin fiyatı \%10.36 oranında artmaktadır. Oysa Fisher Miktar Teorisine göre parasal varlığın miktarı ile değeri ya da yarattığı alım gücü arasında ters bir orantı olması beklenir. Görüldügüüüzere Bitcoinde bu durumun tersi söz konusudur, Fisher Miktar Teorisi geçerli değildir. Bunun temel nedeni sonuç bölümünde açıklanmıştır. Model 4'e göre Bitcoin arzı sıfırken, değeri $0.87 \mathrm{ABD}$ doları olarak tespit edilmiştir.

Covid-19 salgını dönemini kapsayan Model 5'e göre kripto para miktarı ile piyasa değeri arasındaki doğrusal ilişki artmıştır. Salgın döneminde Bitcoin miktarındaki \%1 artış, Bitcoinin piyasa değerini \%27.05 düzeyinde artırmaktadır. Bununla birlikte sabit katsayı 0.87 ABD dolarından, 0.88 ABD dolarına yükselmişsir. Bu sonuçlar çalışmanın temel hipotezini desteklemekte ve madencilik faaliyetlerinin yapısı gereği, Bitcoinin piyasa değerine olumlu etki edeceği söylemini desteklemektedir. 
Kukla değişken olarak eklenen yıllarda ise yine kripto para miktarı ile değeri arasında artışlar bulunmaktadır. Bu artışlar sabitte gerçekleşmiştir.

\section{Sonuç}

Çalışma kapsamında temel kripto para olan Bitcoin için miktar teorisi test edilmiştir. Geleceğin parası olarak ünvanlandırılan kripto paraların pek çok açıdan geleneksel paralara göre farklılıklar gösterdiği açıktır. Bu çalışma söz konusu farklılığın miktar teorisi açısından da geçerli olduğunu ortaya koymuştur. Fisher Miktar Teorisine göre paranın miktarı ile değeri ya da alım gücü arasında ters yönlü ilişki olmalıdır; oysa bu çalışma kripto paraların miktarı ile değeri arasında doğrusal bir ilişki olduğunu ortaya koymuş ve bunu kripto paraların madencilik faaliyetlerinin yapılış şekillerine bağlamıştır.

Yapılan ekonometrik analizin sonucuna göre temel kripto para olan Bitcoinin miktarı, Bitcoin fiyatını pozitif yönde etkilemektedir. Bunun nedeni blok zincir yönteminin temelleri ile ilişkili olabilecektir. Blok zincir yönteminde para arzı madencilik faaliyetleri ile açığa çıkmaktadır. Madencilik faaliyetleri ise bireylerin Bitcoine ilgisini artırmaktadır. Dolayısıyla Bitcoinde para arzı, Bitcoinin birim değerini ters yönde etkilemediği gibi doğrusal olarak artırmaktadır. Görülmektedir ki bu doğrusal ilişkide Covid-19 salgın hastalığı ile birlikte hem otonom bir artış hem de eğimde bir artış meydana gelmiştir.

Çalışma kapsamında paranın tarihsel gelişimi içinde kripto paralar değerlendirilmiştir. Geçmişte oldukça katı olan para ve finans sistemleri günümüzde dönüşüme daha açık ve esnek bir yapıdadır. Kripto paralar ortaya çıkış biçimleri ile incelendiğinde, diğer para biçimlerinin çıkışıyla benzerlik göstermektedir. Çağımızla birlikte ödeme ve parasal işlemlerde yeni gereksinimlerin olduğu açıktır. Diğer para türlerinin de bu tür gereksinimlere yanıt vermesi sonucu ortaya çıktığı düşünülürse kripto paraların gelecekte kullanım alanlarını genişleteceği çıkarımını yapmak oldukça kolaydır. Bu bağlamda rekabetçi tavır tutunan ülke, şirket ve bireylerin bu tür paraları portföylerine eklemesi elzemdir. 
Her kripto parada madencilik faaliyetleri farklı kurallara dayalı olabilmektedir. Yine her kripto para için farklı rezerv miktarları belirlenmiş ve bu rezerv miktarları açıklanmıştır. 2021 Nisan ayı itibari ile rezerv sınırı belirsiz kripto para bulunmamaktadır. Ancak bu çalışma rezerv sınırı belirsiz kripto paraların bireylerin ilgisini daha da canlandırabileceğini savunmaktadır. Bununla birlikte madencilik faaliyetlerinin elektrik tüketimi gerektirecek işlemler yerine sayısal kurallara dayalı olarak gerçekleşmesi kripto paraların üretim ve işlem maliyetlerini düşürerek sürdürebilirlik sağlayabilecektir.

\footnotetext{
Hakem Değerlendirmesi: Dış bağımsız.

Çıkar Çatışması: Yazarlar çıkar çatışması bildirmemiştir.

Finansal Destek: Yazarlar bu çalışma için finansal destek almadığını beyan etmiştir.

Peer-review: Externally peer-reviewed.

Conflict of Interest: The authors have no conflict of interest to declare.

Grant Support: The authors declared that this study has received no financial support.
}

\section{Kaynaklar/References}

Aksoy, E. E. (2018). Bitcoin paradan sonraki en büyük icat (3.bs). İstanbul: Abaküs.

Antonopoulos, A. M. (2015). Mastering bitcoin. Sebastopol: O'Reilly Media, Inc.

Armknecht F., Karame G.O., Mandal A., Youssef F., Zenner E. (2015) In: Conti M., Schunter M., Askoxylakis I. (Ed.), Trust and Trustworthy Computing. Lecture Notes in Computer Science: Vol. 9229. Ripple: Overview and Outlook. içinde (s.163-180). Cham, Springer. https://doi. org/10.1007/978-3-319-22846-4_10

Ay, i. C. (2021). Air pollution, health and economic growth: A panel data analysis for countries with the highest co2 emission. Akademik Hassasiyetler, 8(15), 269-288.

Breusch, T. S., \& Pagan, A. R. (1979). A simple test for heteroscedasticity and random coefficient variation. Econometrica, 47(5), 1287-1294. https://doi.org/10.2307/1911963

Brunton, F. (2019). Digital cash: The unknown history of the anarchists, utopians, and technologists who created cryptocurrency. Princeton: Princeton University Press.

Chohan, U. W. (2021). A history of dogecoin discussion series: Notes on the 21st century. Erişim adresi: https://ssrn.com/abstract=3091219 veya http://dx.doi.org/10.2139/ssrn.3091219

Cochrane, D., \& Orcutt, G. H. (1949). Application of least squares regression to relationships containing auto- correlated error terms. Journal of the American Statistical Association, 44(245), 32-61. https://doi.org/10.2307/2280349

Coin Market Cap. (2021). https://coinmarketcap.com

Çarkacıoğlu, A. (2016). Kripto-para bitcoin. Sermaye Piyasası Kurulu Araştırma Dairesi Araştırma Raporu. 
Dickey, D. A., \& Fuller, W. A. (1979). Distribution of the estimators for autoregressive time series with a unit root. Journal of the American Statistical Association, 74(366), 427-431. https://doi. org/10.2307/2286348

Durbin, J., \& Watson, G. S. (1950). Testing for serial correlation in least squares regression. I. Biometrika, 37(3/4), 409-428. https://doi.org/10.2307/2332391

Durbin, J., \& Watson, G. S. (1971). Testing for serial correlation in least squares regression. III. Biometrika, 58(1), 1-19. https://doi.org/10.2307/2334313

Fisher, I. (1911). The purchasing power of money: Its determination and relation to credit interest and crises (Harry G. B). New York: The Macmilan Co.

Friedman, M. (1969). The optimum quantitiy of money and other essays. London: Macmillan.

Humphrey, T. M. (1974). The quantity theory of money: Its historical evolution and role in policy debates. Economic Review, 60(5), 2-19. Erişim adresi: https://www.richmondfed.org/publications/ research/economic_review/1974/er600301

Hurlburt, G. F., \& Bojanova, I. (2014). Bitcoin: Benefit or curse? It Professional, 16(3), 10-15. https:// doi.org/10.1109/MITP.2014.28

Inci, A. C., \& Lagasse, R. (2019). Cryptocurrencies: Applications and ınvestment opportunities. Journal of Capital Markets Studies, 3(2), 98-112. https://doi.org/10.1108/JCMS-05-2019-0032

Keynes, J. M. (1937). The general theory of employment. The Quarterly Journal of Economics, 51(2), 209-223. https://doi.org/10.2307/1882087

Marian, O. (2016). Is cryptographıc currency an outstandıng tax heaven? Istanbul Üniversitesi Hukuk Fakültesi Mecmuası, 74(2), 919-930. Erişim Adresi: https://dergipark.org.tr/tr/pub/iuhfm/ issue $/ 28495 / 305044$

Marshall, A. (1923). Money, credit \& commerce. London: Macmillan \& Co.

Nakamoto, S. (2008). Bitcoin: A peer-to-peer electronic cash system, Erişim adresi: https://Bitcoin.Org/ Bitcoin.Pdf.

Newey, W. K., \& West, K. D. (1987). A simple, positive semi-definite, heteroskedasticity and autocorrelation consistent covariance matrix. Econometrica, 55(3), 703-708. https://doi. org/10.2307/1913610

Özdemir, O., \& Kayhan, F. (2019). The effect of global financial crisis on securities portfolio of deposit banks: A difference-ın-differences method for turkey. Business \& Management Studies: An International Journal, 7(1), 444-466. https://doi.org/10.15295/bmij.v7i1.1082

Peck, M. E. (2012). The crypto anarchists' answer to cash. IEEE Spectrum, 49(6), 50-56. https://doi. org/10.1109/MSPEC.2012.6203968

Phillips, P. C., \& Perron, P. (1988). Testing for a unit root in time series regression. Biometrika, 75(2), 335-346. https://doi.org/10.1093/biomet/75.2.335

Pigou, A. C. (1917). The value of money. The Quarterly Journal of Economics, 32(1), 38-65. https:// doi.org/10.2307/1885078 
Rotman, S. C. (2014). Bitcoin versus electronic money. The World Bank, No: 88164, 1-4. Erişim adresi: https://openknowledge.worldbank.org/bitstream/ handle/10986/18418/881640BRI0 Box30WLEDGENOTES0Jan02014.pdf? sequence $=1$

Shimazu, R. (1969). A reconsideratıon of the quantity theory of money. Kyoto University Economic Review, 39(1), 45-62. https://doi.org/10.11179/ker1926.39.45

Sontakke, K. A., \& Ghaisas, A. (2017). Cryptocurrencies: A developing asset class. International Journal of Business Insights \& Transformation, 10(2), 10-17. https://doi.org/10.1080/154049 6X.2016.1193002

Stolbov, M., \& Shchepeleva, M. (2020). What predicts the legal status of cryptocurrencies? Economic Analysis and Policy, 67, 273-291. https://doi.org/10.1016/j.eap.2020.07.011

Sun, T., \& Yu, W. (2020). A formal verification framework for security issues of blockchain smart contracts. Electronics, 9(2), 255-278. https://doi.org/10.3390/electronics9020255

Şişman, D. (2015). Ulusötesi şirketler ve küresel kriz. Marmara Üniversitesi İktisadi ve İdari Bilimler Dergisi, 37(2), 341-368.

Tredinnick, L. (2019). Cryptocurrencies and the blockchain. Business Information Review, 36(1), 3944. https://doi.org/10.1177/0266382119836314

Turan, Z. (2018). Kripto paralar, bitcoin, blokzinciri, petro gold, dijital para ve kullanım alanları. Ömer Halisdemir Üniversitesi İktisadi ve İdari Bilimler Fakültesi Dergisi, 11(7), 1-5.

Usta, A., \& Doğantekin, S. (2017). Blockchain 101 (2.bs). İstanbul: MediaCat Kitapları, Kapital Medya Hizmetleri A.Ş.

White, H. (1980). A heteroskedasticity-consistent covariance matrix estimator and a direct test for heteroskedasticity. Econometrica, 48(4), 817-838. https://doi.org/10.2307/1912934

Young, I. (2018). Dogecoin: A brief overview \& survey. Erişim adresi: https://ssrn.com/ abstract=3306060 veya http://dx.doi.org/10.2139/ssrn.3306060 